\title{
Validity and reliability of the Italian version of the cardiac quality of life questionnaire for pediatric patients with heart disease (PedsQLTM)
}

Teresa Grimaldi Capitello ${ }^{1 *} \odot$, Francesca Bevilacqua ${ }^{1}$, Roberta Vallone ${ }^{1}$, Anna Maria Dall'Oglio', Francesca Santato', Salvatore Giannico ${ }^{2}$, Giulio Calcagni², Simone Piga ${ }^{3}$, Marta Ciofi degli Atti ${ }^{3}$, Simonetta Gentile ${ }^{1}$ and Angela Rossi ${ }^{1}$

\begin{abstract}
Background: Congenital heart disease (CHD) accounts for nearly a third of all major congenital anomalies. Advances in pediatric cardiology shifted attention from mortality to morbidity and health-related quality of life (HRQOL) of patients with CHD and impact on their families. The purposes of this study were to assess the validity and reliability of the Italian version of the Pediatric Quality of Life (PedsQL) Cardiac Module and to create normative data for the Italian population.

Methods: This was an observational cross-sectional study of pediatric patients (aged 2-18 years) with congenital or acquired Heart Disease (HD) and their parents. Families were asked to complete the cardiac pediatric healthrelated quality of life questionnaire (the Italian PedsQL ${ }^{\mathrm{TM}} 3.0$ Cardiac Module) and the generic pediatric health-related quality of life questionnaire (PedsQL ${ }^{\mathrm{TM}} 4.0$ Generic Core Scales). The sequential validation procedure of the original United States version of the PedsQL ${ }^{\mathrm{TM}} 3.0$ Cardiac Module was carried out under the instruction of the MAPI Research Institute.

To assess construct validity, Pearson's correlation coefficients were assessed between scores on the Cardiac Module scales and scores on the scales of the General Module. To determine agreement between patient self-report and parent proxy-report, we used intraclass correlation coefficients (ICCS). To evaluate Internal consistency of items, we used Cronbach's alpha Coefficient.
\end{abstract}

Results: The study enrolled 400 patients. Construct validity is good between PedsQL Cardiac Module total scores and PedsQL total scores $(p<0.001)$. The recommended standard value of 0.7 was reached on the Cardiac and General Module core scales. Intercorrelations between PedsQL Cardiac module and PedsQL scores revealed medium to large correlations. In general, correlations between Patient self-reports are poorer than Parent-proxy ones.

Conclusions: Cardiac PedsQL scores are valid and reliable for pediatric patients with congenital and acquired HD and may be useful for future research and clinical management.

\footnotetext{
${ }^{*}$ Correspondence: teresa.grimaldi@opbg.net

${ }^{1}$ Unit of Clinical Psychology, Department of Neuroscience, Bambino Gesù

Children's Hospital, IRCCS, Rome, Italy

Full list of author information is available at the end of the article
}

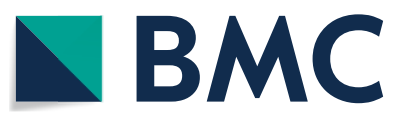

(C) The Author(s) 2021. Open Access This article is licensed under a Creative Commons Attribution 4.0 International License, which permits use, sharing, adaptation, distribution and reproduction in any medium or format, as long as you give appropriate credit to the original author(s) and the source, provide a link to the Creative Commons licence, and indicate if changes were made. The images or other third party material in this article are included in the article's Creative Commons licence, unless indicated otherwise in a credit line to the material. If material is not included in the article's Creative Commons licence and your intended use is not permitted by statutory regulation or exceeds the permitted use, you will need to obtain permission directly from the copyright holder. To view a copy of this licence, visit http://creativecommons.org/licenses/by/4.0/. The Creative Commons Public Domain Dedication waiver (http://creativeco mmons.org/publicdomain/zero/1.0/) applies to the data made available in this article, unless otherwise stated in a credit line to the data. 
Keywords: Health-related quality of life, Pediatric heart diseases, PedsQL cardiac module

\section{Background}

Congenital heart diseases (CHD) accounts for nearly a third of all major congenital anomalies. The reported incidence of congenital heart disease (CHD) is 7-9 per 1000 live births and remains the leading cause of death for children under 1 year of age [1]. Literature does not provide certain and unambiguous data on the incidence of acquired heart diseases in pediatric population [2]. In recent decades, new surgical techniques and advances in cardiopulmonary bypass, intensive care, heart transplantation, and interventional catheterization have significantly reduced mortality rates for children with heart diseases (HD). Consequently, an increasing number of children are living with chronic HD, $85-90 \%$ of whom will reach adulthood, although many of them will require lifelong follow-up [3, 4]. These advances in pediatric cardiology have an influence on morbidity, quality of life (QOL), and health-related quality of life (HRQOL) of children with heart disease, and the impact on their families [4]. Chronic heart disease is often associated with physical symptoms and may impair the patient's psychological and social well-being and functioning. Therefore, in order to increase overall understanding of the disease, specific tools for assessment of health-related quality of life are advocated [5, 6]. HRQOL is a multidimensional construct which includes physical, psychological and social well-being and functioning [7].

The Pediatric Quality of Life Inventory Version 4.0 Generic Core Scales (PedsQL) is one of the main instruments for measuring pediatric patients' health related quality of life and one of the very few instruments widely used to assess HRQOL among patients between the ages of 2 and 18 years [8]. PedsQL includes patient and parent versions and assesses different dimensions: physical, emotional, social, and school functioning [9]. Moreover, in order to evaluate $\mathrm{HRQ}$ oL according to specific clinic conditions, Authors have developed disease-specific modules concerning, for example, ADHD, cancer, asthma and heart disease [10-15]. In particular, Uzark et al. determined reliability and validity of the PedsQL ${ }^{\mathrm{TM}} 3.0$ Cardiac Module as a brief, multidimensional measure of health related quality of life in pediatric cardiology [15]. The instrument has five scales related to symptoms (7 items), perceived physical appearance (3 items), treatment anxiety (4 items), cognitive problems ( 5 items), and communication (3 items) for parent proxy-report and pediatric patients $8-18$ years. The communication scale was not included for toddlers and young children who do not have the cognitive or language ability to verbalize questions and explanations about the heart. An additional treatment barriers scale (5 items) was imbedded in the module to measure adherence issues in subjects taking cardiac medications [15].

The aim of this study was to produce an Italian version of the PedsQL Cardiac Module that is semantically and culturally equivalent to the original English version and to assess its psychometric properties in a sample of pediatric patients with heart disease between 2 and 18 years of age.

\section{Methods}

This was an observational cross-sectional study of pediatric patients with congenital or acquired Heart Disease (HD) and their parents. It was performed at Bambino Gesù Children's Hospital and Research Institute between September 2016 and December 2017. The study involved patients aged 2-18 with congenital or acquired HD attending an outpatient cardiology unit. Exclusion criteria: major developmental delay that could affect healthrelated quality of life, developmental problems that limited understanding and/or verbal communication, language barrier. Parents or legal tutors of all patients signed a detailed written informed consent, all patients above 16 years of age signed a written informed assent. All eligible, consenting/assenting patients and parents were enrolled in the study. Participants completed a battery of questionnaires that included: a family form to collect socio-demographic information, the PedsQL ${ }^{\mathrm{TM}} 3.0$ Cardiac Module, and the Italian version of the PedsQL Generic Core Scales 4.0.

As described in previous studies by Uzark et al., do Nascimento et al. and Berkes et al., the PedsQL ${ }^{\mathrm{TM}} 3.0$ Cardiac Module presents a list of items to the patients/parents and asks them to report how problematic each item has been for the patient in the past month $[6,15,16]$. The Cardiac Module provides child self-report and parent proxy-report forms. Ages for child self-report forms are: $5-7,8-12$ and $13-18$ years. In parallel, ages for parent proxy-report forms are: $2-4$ (toddler), $5-7$ (young child), 8-12 (child), and 13-18 (adolescent). In parent-proxy report forms parents are asked to evaluate their child's HRQOL. Five answer options are listed in the versions for patients 8 to 18 years old and for all versions for parents $(0=$ it is never a problem; $1=$ it is almost never a problem; $2=$ it is sometimes a problem; $3=i$ is often a problem; and $4=$ it is almost always a problem). The answers in the version for children 5-7 years old was simplified to three options $(0=$ not at all; $2=$ sometimes; and $4=$ a lot $)$ 
on a visual scale that exhibited a happy, neutral, and sad face, respectively. As to the scoring, answer options must be transformed as follows: $0=100 ; 1=75 ; 2=50 ; 3=25$; and $4=0$. Higher scores indicated a better HRQOL. The sum of all the items over the number of items answered provides mean score. Child self-report and parent proxyreport formats are shown in Additional file 1.

The instruction of the MAPI Research Institute, in accordance with the guidelines of the QOL-SIG TCA (Quality of Life-Special Interest Group Translation and Cultural Adaptation) group, were followed for the validation procedure of the original U. S. version of the Ped$\mathrm{sQL}^{\mathrm{TM}} 3.0$ Cardiac Module [6, 15-21].

As described in above-cited studies, the validation process begins with two professional native language speakers' translators who translate the PedsQL ${ }^{\mathrm{TM}} 3.0$ Cardiac Module independently into Italian. Both translators debated the two translated versions with a pediatric cardiologist creating a single agreed version that was translated back into English. This version was sent to the questionnaire's author for comments and approval. Cognitive interviews with 8 couples of parents of patients with HD aged 2-18 years and with 8 patients aged 5-18 years were performed to control if each item was simple enough to be understood. MAPI Research Institute gave its approval to the so-built final version.

As described by Uzark et al., the PedsQL ${ }^{\mathrm{TM}} 4.0$ Generic Core Scales encompasses Physical Functioning (8 items), Emotional Functioning (5 items), Social Functioning (5 items), and School Functioning (5 items) [15]. The Ped$\mathrm{sQL}^{\mathrm{TM}}$ provides child self-report and parent proxy-report forms. Ages for child self-report forms are: 5-7, 8-12 and 13-18 years. In parallel, ages for parent proxy-report forms are: $2-4,5-7,8-12$ and $13-18$ years. In parentproxy report forms parents are asked to evaluate their child's HRQOL. Five answer options are listed in the versions for patients 8 to 18 years old and for all versions for parents $(0=i$ it is never a problem; $1=$ it is almost never a problem; $2=$ it is sometimes a problem; $3=i$ is often a problem; and $4=$ it is almost always a problem). The answers in the version for children 5-7 years old was simplified to three options $(0=$ not at all; $2=$ sometimes; and $4=\mathrm{a}$ lot) on a visual scale that exhibited a happy, neutral, and sad face, respectively. As to the scoring, answer options must be transformed as follows: $0=100$; $1=75 ; 2=50 ; 3=25$; and $4=0$. Higher scores indicated a better HRQOL. The sum of all the items over the number of items answered provides mean score.

\section{Statistical analysis}

We describe the clinical and demographic characteristics of all the patients enrolled in this study. We calculated descriptive statistics and report mean \pm SDs or median with IQR and ranges as appropriate for the data distribution. We report percentages for categorical or dichotomous variables.

Acceptability of this study was determined by the low percentage of missing values.

Since the response items were expressed on an ordinal scale, we used Cronbach coefficient to evaluate scale internal consistency reliability [22]. Psychological scales with internal consistency reliabilities of 0.90 are usually recommended for analysing individual patient scores, whereas an internal consistency reliability criterion of 0.70 is recommended for comparing patient groups [23]. Range of measurement was based on the percentage of scores at the minimum and maximum of the scaling range, that is, the minimum possible score (floor effect matches at percentage of scale scores at 0 ) and the maximum possible score (ceiling effect matches percentage of scale scores at 100).

Study with moderate floor or ceiling effects ( $>15 \%)$ are considered less precise in measuring latent constructs at the extremes of the scale, similarly study with small floor or ceiling effects (1-15\%) are considered to meet acceptable measurement standards [24].

Construct validity was assessed by examining Pearson's correlation coefficients between scores on the Cardiac Module scales and scores on the scales of the General Module. Pearson Correlation coefficients are defined small if $r<0.30$, medium if $r \geq 0.30$ and $r \leq 0.50$, and large if $r \geq 0.50$ [24]. In this regard, we expected large correlations between Cardiac Module total score and Generic Core Scales total score; Heart Problems and Treatment (Cardiac module) and Physical Health (Generic module); Cognitive Problems (Cardiac module) and School Functioning (Generic module).

Since the considered variables can be treated as continuous variables, we used intra-class correlation coefficients (ICCs) to determine agreement between patient self-report and parent proxy-report because it takes into account the ratio between subject variability and total variability [25]. ICCs are defined poor if agreement are less than 0.40 , between 0.41 and 0.60 are defined moderate agreement, between 0.61 and 0.80 are good agreement, and between 0.81 and 1.00 are excellent agreement [26].

Statistical significance was assumed as $p<0.05$ for all tests. All statistical analyses were performed using STATA, Statistical Software: Release 13. College Station, Tx: StataCorp 2013.

\section{Results}

Subjects' demographic characteristics

Families of 400 patients were consecutively enrolled in the study. In 318 families, only one parent filled up the 
Table 1 Demographic characteristics

\begin{tabular}{|c|c|c|c|c|c|c|c|c|c|c|}
\hline \multirow[t]{2}{*}{ Demographic variables } & \multicolumn{2}{|c|}{$2-4$ years } & \multicolumn{2}{|c|}{$5-7$ years } & \multicolumn{2}{|c|}{$8-12$ years } & \multicolumn{2}{|c|}{ 13-18 years } & \multicolumn{2}{|l|}{ Total } \\
\hline & \multicolumn{2}{|c|}{$\mathrm{N}=37$} & \multicolumn{2}{|c|}{$\mathrm{N}=68$} & \multicolumn{2}{|c|}{$\mathrm{N}=185$} & \multicolumn{2}{|c|}{$\mathrm{N}=110$} & \multicolumn{2}{|c|}{$\mathrm{N}=400$} \\
\hline \multicolumn{11}{|l|}{ Children } \\
\hline Female N(\%) & 16 & 43.2 & 26 & 38.2 & 89 & 48.1 & 44 & 40.0 & 175 & 43.8 \\
\hline Parents & \multicolumn{2}{|c|}{$\mathrm{N}=60$} & \multicolumn{2}{|c|}{$N=101$} & \multicolumn{2}{|c|}{$N=197$} & \multicolumn{2}{|c|}{$N=124$} & \multicolumn{2}{|c|}{$\mathrm{N}=482$} \\
\hline Mothers N(\%) & 36 & 60.0 & 61 & 60.4 & 121 & 61.4 & 73 & 58.9 & 291 & 60.4 \\
\hline Fathers N(\%) & 24 & 40.0 & 40 & 39.6 & 76 & 38.6 & 51 & 41.1 & 191 & 39.6 \\
\hline Cohabiting parents N(\%) & 27 & 73.0 & 61 & 89.7 & 161 & 87.1 & 89 & 80.9 & 338 & 84.5 \\
\hline Single/divorced N(\%) & 10 & 27.0 & 7 & 10.3 & 24 & 12.9 & 21 & 19.1 & 62 & 15.5 \\
\hline Age M(sd) & 37.3 & 6.2 & 41.5 & 5.0 & 43.4 & 5.5 & 48.6 & 6.0 & 42.7 & 5.7 \\
\hline \multicolumn{11}{|l|}{ Educational level N(\%) } \\
\hline Compulsory education & 7 & 11.7 & 15 & 14.9 & 38 & 19.3 & 17 & 13.7 & 77 & 16.0 \\
\hline High school & 30 & 50.0 & 46 & 45.5 & 92 & 46.7 & 69 & 55.6 & 237 & 49.2 \\
\hline Degree & 23 & 38.3 & 40 & 39.6 & 67 & 34.0 & 38 & 30.7 & 168 & 34.8 \\
\hline \multicolumn{11}{|l|}{ Work N(\%) } \\
\hline Employed & 45 & 75.0 & 76 & 75.2 & 141 & 71.5 & 89 & 71.8 & 351 & 72.9 \\
\hline Unemployed & 6 & 10.0 & 5 & 5.0 & 9 & 4.6 & 13 & 10.5 & 33 & 6.8 \\
\hline Homemakers & 9 & 15.0 & 20 & 19.8 & 47 & 23.9 & 22 & 17.7 & 98 & 20.3 \\
\hline
\end{tabular}

Table 2 Heart diseases

\begin{tabular}{|c|c|c|c|c|c|c|c|c|c|c|}
\hline & \multirow{2}{*}{\multicolumn{2}{|c|}{$\begin{array}{l}2-4 \text { years } \\
\mathrm{N}=37\end{array}$}} & \multirow{2}{*}{\multicolumn{2}{|c|}{$\begin{array}{l}5-7 \text { years } \\
N=68\end{array}$}} & \multirow{2}{*}{\multicolumn{2}{|c|}{$\begin{array}{l}8-12 \text { years } \\
N=185\end{array}$}} & \multirow{2}{*}{\multicolumn{2}{|c|}{$\begin{array}{l}\text { 13-18 years } \\
\mathrm{N}=110\end{array}$}} & \multirow{2}{*}{\multicolumn{2}{|c|}{$\begin{array}{l}\text { Total } \\
\mathrm{N}=400\end{array}$}} \\
\hline & & & & & & & & & & \\
\hline & $\mathbf{N}$ & (\%) & $\mathbf{N}$ & (\%) & $\mathrm{N}$ & (\%) & $\mathbf{N}$ & $(\%)$ & $\mathrm{N}$ & (\%) \\
\hline Aortic anomalies ${ }^{\mathrm{a}}$ & 11 & (29.8) & 24 & (35.3) & 67 & $(36.2)$ & 48 & $(43.6)$ & 150 & (37.5) \\
\hline Univentricular heart physiology ${ }^{\mathrm{a}}$ & 4 & $(10.8)$ & 4 & (5.9) & 15 & $(8.1)$ & 12 & $(10.9)$ & 35 & (8.8) \\
\hline Tetralogy of fallot ${ }^{\mathrm{a}}$ & 4 & $(10.8)$ & 11 & $(16.2)$ & 33 & $(17.8)$ & 25 & $(22.7)$ & 73 & $(18.2)$ \\
\hline RV-PA conduit ${ }^{\mathrm{a}, \mathrm{c}}$ & 2 & $(5.4)$ & 7 & $(10.3)$ & 13 & $(7.1)$ & 6 & $(5.4)$ & 28 & $(7.0)$ \\
\hline Transposition of great arteries ${ }^{a}$ & 5 & (13.5) & 9 & $(13.2)$ & 33 & $(17.8)$ & 11 & $(10.0)$ & 58 & (14.6) \\
\hline Cardiomyopathy $^{\mathrm{b}}$ & 1 & $(2.7)$ & 1 & (1.5) & 3 & (1.6) & 4 & (3.7) & 9 & $(2.2)$ \\
\hline Others & 10 & $(27.0)$ & 12 & (17.6) & 21 & (11.4) & 4 & (3.7) & 47 & (11.7) \\
\hline
\end{tabular}

${ }^{a}$ Congenital heart disease

${ }^{\mathrm{b}}$ Acquired heart disease

${ }^{\mathrm{c}} \mathrm{RV}$-PA conduit group includes all patients requiring a connection between RV to PA through a conduit instead of the natural RV outflow tract

questionnaires, in 82 families both parents filled up the questionnaires. Of the 482 parents who took part in the study, 291 (60.4\%) were mothers and 191 (39.6\%) were fathers. Sociodemographic data of the sample are shown in Table 1.

\section{Subjects' heart clinical characteristics}

Heart diagnosis of the 400 patients and their distribution in age cluster are shown in Table 2. It was not possible to conduct comparisons with a group of healthy children and the cardiologists considered the categories not comparable by disease severity.
Association of PedsQL cardiac module with PedsQL scores Internal consistency-reliability

The internal consistency-reliability values of the 2 modules are presented in Tables 3 and 4, respectively. The recommended standard value of 0.7 was reached on the Cardiac and General Module core scales. Internal consistency was more than 0.7 for some dimensions in the different age groups. Patients in 5-18 age groups and Parents in $2-18$ age groups presented high values in Treatment Anxiety scale and Communication scale in Cardiac Module (Table 5). 
Table 3 Internal consistency reliability of patients PedsQL cardiac module and patients PedsQL generic module (Cronbach coefficient)

\begin{tabular}{|c|c|c|c|c|c|c|}
\hline \multirow[t]{2}{*}{ Patient } & \multicolumn{3}{|c|}{$5-7$ years } & \multicolumn{3}{|c|}{ 8-18 years } \\
\hline & All & Male & Female & All & Male & Female \\
\hline \multicolumn{7}{|l|}{ PedsQL cardiac module } \\
\hline Total SCORE & 0.70 & 0.70 & 0.79 & 0.82 & 0.82 & 0.85 \\
\hline Heart problems and treatment & 0.64 & 0.55 & 0.74 & 0.63 & 0.68 & 0.62 \\
\hline Treatment II & 0.80 & 0.80 & 0.80 & 0.50 & 0.61 & 0.49 \\
\hline Perceived physical appearance & 0.67 & 0.63 & 0.76 & 0.71 & 0.68 & 0.72 \\
\hline Treatment anxiety & 0.94 & 0.91 & 0.97 & 0.88 & 0.87 & 0.90 \\
\hline Cognitive problems & 0.63 & 0.62 & 0.66 & 0.70 & 0.60 & 0.77 \\
\hline Communication & 0.88 & 0.85 & 0.92 & 0.74 & 0.71 & 0.74 \\
\hline \multicolumn{7}{|l|}{ PedsQL generic module } \\
\hline Total score & 0.82 & 0.77 & 0.87 & 0.84 & 0.82 & 0.85 \\
\hline Physical functioning & 0.72 & 0.65 & 0.79 & 0.73 & 0.72 & 0.73 \\
\hline Emotional functioning & 0.56 & 0.51 & 0.59 & 0.58 & 0.52 & 0.59 \\
\hline Social functioning & 0.71 & 0.62 & 0.86 & 0.74 & 0.59 & 0.74 \\
\hline School functioning & 0.72 & 0.70 & 0.77 & 0.73 & 0.69 & 0.77 \\
\hline
\end{tabular}

However, internal consistency was less than 0.7 for some dimensions such as Heart Problems and Treatment scale in Cardiac Module in Patients in 5-18 age groups, in Perceived Physical Appearance scale in Cardiac Module in Children and Parents in 5-7 age groups, and in Cognitive Problems scale in Cardiac Module in Children in 5-7 age groups and Parents in 2-7 age groups.

Internal consistency was more than 0.7 for some dimensions of the Generic Module such as Emotional Functioning in Parents and Patients in 8-18 age groups and School Functioning in Parents in 2-4 age groups in Generic Module.

When considering patients' gender, some differences were found for internal consistency reliability scores for female versus male patients (Table 3 ).

Comparison of patient and parent in PedsQL Cardiac module and PedsQL scores Intercorrelations between PedsQL Cardiac module and PedsQL scores revealed medium to large correlations. In general, correlations between Patient self-reports are poorer than Parentproxy ones.

As hypothesized, PedsQL Cardiac Module total score correlates with PedsQL total score in all age clusters and for both the Patient version and Parent version $r>0.38$ and $r>0.88(p<0.001)$; Heart Problems and treatment score correlates with Physical Health score $r>0.47$ and $r>0.92(p<0.001)$; Cognitive problems score $(r>0.41, p<0.001)$ correlates with School functioning $\mathrm{r}>0.79, p<0.001)$.
Parent-patient agreement in cardiac module The ICCs between Patient self-reports and Parent proxy-reports of the PedsQL ${ }^{\mathrm{TM}}$ 3.0 Cardiac Module are given in Table 6. The results obtained were: moderate to good values in both patient and parent groups in the Cardiac Scale; lower values in the Heart problems and treatment, Cognitive problems and Communication Scales across all age groups, and in the Perceived Physical appearance and Treatment anxiety Scales in 8-18 year-olds from the patient group.

Intraclass Correlations (ICC) showed good agreement in the Perceived Physical appearance and Treatment anxiety Scale scores of children aged 5-7 years and in Treatment II Scale scores of Patients age 8-18 years. ICCs for the Cardiac Module indicated excellent agreement in Treatment II scale in the 5-7 age group.

Additional file 2 shows Reliability and percent Floor and Ceiling Effects for Child Self Report and Parent Proxy-Report for PedsQL ${ }^{\mathrm{TM}}$ 3.0 Cardiac Module (Table 7) and PedsQL Generic Core Scales 4.0 (Table 8).

\section{Discussion}

The aim of the present study was to assess psychometric properties of the Italian version of the PedsQL ${ }^{\mathrm{TM}} 3.0 \mathrm{Car}$ diac Module and the PedsQL ${ }^{\mathrm{TM}} 4.0$ Generic Core Scale in CHD population. Overall, our results show that the Italian translation of the PedsQL ${ }^{\mathrm{TM}} 3.0$ Cardiac Module is a valid tool to assess HRQoL of Italian pediatric patients with $\mathrm{CHD}$ aged $2-18$ years.

In particular, internal consistency was generally satisfactory, but nevertheless below the recommended standard value for some dimensions such as Heart Problems and Treatment Scale in patients 5-18 age 
Table 4 Internal consistency reliability of parents PedsQL cardiac module and parents PedsQL generic module (Cronbach coefficient)

\begin{tabular}{|c|c|c|c|}
\hline & $2-4$ years & $5-7$ years & $8-18$ years \\
\hline \multicolumn{4}{|l|}{ PedsQL cardiac module } \\
\hline \multicolumn{4}{|l|}{ Mothers } \\
\hline Total score & 0.57 & 0.82 & 0.89 \\
\hline Heart problems and treatment & 0.79 & 0.80 & 0.76 \\
\hline Treatment II & 1.00 & 1.00 & 0.56 \\
\hline Perceived physical appearance & 0.68 & 0.49 & 0.80 \\
\hline Treatment anxiety & 0.95 & 0.94 & 0.94 \\
\hline Cognitive problems & 0.50 & 0.69 & 0.84 \\
\hline Communication & 1.00 & 0.76 & 0.84 \\
\hline \multicolumn{4}{|l|}{ Fathers } \\
\hline Total score & 0.84 & 0.70 & 0.90 \\
\hline Heart problems and treatment & 0.75 & 0.80 & 0.82 \\
\hline Treatment II & 1.00 & 0.79 & 0.78 \\
\hline Perceived physical appearance & 1.00 & 0.55 & 0.76 \\
\hline Treatment anxiety & 0.96 & 0.95 & 0.93 \\
\hline Cognitive problems & 0.61 & 0.61 & 0.84 \\
\hline Communication & 0.88 & 0.78 & 0.83 \\
\hline \multicolumn{4}{|l|}{ PedsQL generic module } \\
\hline \multicolumn{4}{|l|}{ Mothers } \\
\hline Total score & 0.91 & 0.82 & 0.82 \\
\hline Physical functioning & 0.91 & 0.72 & 0.72 \\
\hline Emotional functioning & 0.74 & 0.72 & 0.56 \\
\hline Social functioning & 0.86 & 0.71 & 0.71 \\
\hline School functioning & 0.65 & 0.72 & 0.72 \\
\hline \multicolumn{4}{|l|}{ Fathers } \\
\hline Total score & 0.85 & 0.85 & 0.82 \\
\hline Physical functioning & 0.73 & 0.84 & 0.72 \\
\hline Emotional functioning & 0.79 & 0.71 & 0.56 \\
\hline Social functioning & 0.86 & 0.95 & 0.71 \\
\hline School functioning & 0.55 & 0.77 & 0.72 \\
\hline
\end{tabular}

group, Perceived Physical Appearance in patients and parents in the 2-7 age group and in Cognitive Problems in children and their parents in the $2-7$ age group. Similar results had been found in previous studies, Berkes and colleagues in their validation study of the Hungarian Version of PedsQL Cardiac Module ascribe similar results to extremely high frequencies of missing values detected for the Treatment II and Perceived Physical Appearance subscales [6]. In accordance with our results, Gonzales and colleagues, in their validation of the Spanish version, found low internal consistency values in the Perceived Physical Appearance scale, and considered this to be related to the lack of consistency between the items and the neuromaturation and developmental level of the children in the lower age range [27]. Furthermore, when interpreting data of the Cognitive Problems scale, we must remember that in Italy primary school starts from the age of 6, but it frequently happens that children with CHD or other invalidating conditions postpone the beginning of school attending. This might have determined a high percentage of pre-school respondents influencing the data of Cognitive Problems scale. For the same reason, the issue of using school functioning subscale for children aged 2-7 years has been reported as a problem by other European researchers [6, 28, 29].

However, good internal consistency reliability values were found for the Treatment anxiety and Communication Scales, confirming the PedsQL Cardiac Module as a valid measure of the health related quality of life in medical context. This is an interesting finding considering how important it is for clinicians to be aware of how patients experience medical visits and examinations. In fact, as reported by Berkes et al. in accordance with other previous studies, heart diseases had an evident impact on the physical state, but also they considerably influence psychosocial dimensions $[6,7,15,16,30-32]$.

Interestingly, when considering results of the PedsQL Generic Core Scales 4.0, our data showed low internal consistency in the Emotional Functioning dimension, especially in the 8-18 ages group. This finding seems to show a low emotional awareness in CHD patients in everyday life. As suggested by other Authors, these data may reflect patients' emotional distress associated with their cardiac condition (see Additional file 2) [7,33-35].

Lower internal consistency reliability values were calculated in the 2-4 age group for the School Functioning Scales of the Generic Core, which is consistent with previous findings [7]. We must consider that many children in our sample of this age do not attend school because of their disease, and therefore the small sample size could possibly compromise the precision of results.

Intercorrelations between the Cardiac Module Scales and the Generic Scales were significant, in particular the formulated hypothesis (i.e. correlations between total scores; Heart Problems and Treatment vs. Physical Health; Cognitive Problems vs. School Functioning) was confirmed substantiating the construct validity of the tool.

In contrast with previous studies [16], our data showed a poor agreement between child self- and parent proxy-reports, in particular for 8-18 age groups. We can speculate, as reported in literature, a tendency to parental underestimation of QOL and coping mechanisms of chronically ill children which can lead to disagreement $[7,29,33,36,37]$. Health care providers should be aware of the frequent disagreement in HRQoL perception which may result in pediatric 
Table 5 Pearson's correlation coefficients between cardiac and generic module $(n=400)$

\begin{tabular}{|c|c|c|c|c|c|}
\hline & \multicolumn{5}{|l|}{ Generic scales } \\
\hline & Physical health & $\begin{array}{l}\text { Emotional } \\
\text { functioning }\end{array}$ & Social functioning & School functioning & Total \\
\hline \multicolumn{6}{|l|}{ Patient version ( $5-7$ years) } \\
\hline Heart problems and treatment & $0.59^{* * *}$ & 0.135 & $0.291^{*}$ & 0.203 & $0.438^{* * *}$ \\
\hline Treatment II & 0.166 & 0.222 & 0.064 & 0.014 & 0.030 \\
\hline Perceived physical appearance & $0.307^{* *}$ & 0.186 & $0.300^{*}$ & $0.335^{* *}$ & $0.373^{* *}$ \\
\hline Treatment anxiety & 0.167 & 0.166 & 0.045 & 0.074 & 0.155 \\
\hline Cognitive problems & $0.349^{* *}$ & $0.325^{* *}$ & $0.311^{* *}$ & $0.414^{* * *}$ & $0.458^{* * *}$ \\
\hline Communication & $0.373^{* *}$ & 0.052 & $0.400^{* * *}$ & 0.219 & 0.354 \\
\hline Total score & $0.505^{* * *}$ & $0.348^{* *}$ & $0.397^{* * *}$ & 0.382 & $0.545^{* * *}$ \\
\hline \multicolumn{6}{|l|}{ Patient version ( $8-18$ years) } \\
\hline Heart problems and treatment & $0.476^{* * *}$ & $0.380^{* * *}$ & $0.353^{* * *}$ & $0.348^{* * *}$ & $0.458^{* * *}$ \\
\hline Treatment II & 0.040 & 0.021 & 0.017 & 0.064 & 0.001 \\
\hline Perceived physical appearance & 0.045 & $0.121^{*}$ & 0.054 & 0.096 & 0.086 \\
\hline Treatment anxiety & $0.276^{* * *}$ & $0.398^{* * *}$ & $0.210^{* * *}$ & $0.162^{* *}$ & $0.299^{* * *}$ \\
\hline Cognitive problems & $0.361^{* * *}$ & $0.243^{* * *}$ & $0.274^{* * *}$ & $0.477^{* * *}$ & $0.395^{* * *}$ \\
\hline Communication & $0.289^{* * *}$ & $0.232^{* * *}$ & $0.186^{* *}$ & $0.167^{* *}$ & $0.259^{* * *}$ \\
\hline Total score & $0.392^{* * *}$ & $0.361^{* * *}$ & $0.267^{* * *}$ & $0.291^{* * *}$ & $0.384^{* * *}$ \\
\hline \multicolumn{6}{|l|}{ Parent version (5-7 years) } \\
\hline Heart problems and treatment & $0.922^{* * *}$ & $0.789^{* * *}$ & $0.819^{* * *}$ & $0.767^{* * *}$ & $0.892^{* * *}$ \\
\hline Treatment II & 0.053 & 0.183 & 0.084 & 0.102 & 0.103 \\
\hline Perceived physical appearance & $0.579^{* * *}$ & $0.596^{* * *}$ & $0.543^{* * *}$ & 0.449 & 0.581 \\
\hline Treatment anxiety & $0.752^{* * *}$ & $0.784^{* * *}$ & $0.601^{* * *}$ & $0.647^{* * *}$ & $0.746^{* * *}$ \\
\hline Cognitive problems & $0.697^{* * *}$ & $0.645^{* * *}$ & $0.686^{* * *}$ & $0.739^{* * *}$ & $0.739^{* * *}$ \\
\hline Communication & $0.725^{* * *}$ & $0.596^{* * *}$ & $0.649 * * *$ & $0.547^{* * *}$ & $0.684^{* * *}$ \\
\hline Total score & $0.878^{* * *}$ & $0.835^{* * *}$ & $0.796^{* * *}$ & $0.769^{* * *}$ & $0.880^{* * *}$ \\
\hline \multicolumn{6}{|l|}{ Parent version (8-18 years) } \\
\hline Heart problems and treatment & $0.759^{* * *}$ & $0.713^{* * *}$ & $0.735^{* * *}$ & $0.741^{* * *}$ & $0.773^{* * *}$ \\
\hline Treatment II & $0.550^{* * *}$ & $0.517^{* * *}$ & $0.538^{* * *}$ & $0.540^{* * *}$ & $0.562^{* * *}$ \\
\hline Perceived physical appearance & $0.536^{* * *}$ & $0.567^{* * *}$ & $0.556^{* * *}$ & $0.533^{* * *}$ & $0.570^{* * *}$ \\
\hline Treatment anxiety & $0.648^{* * *}$ & $0.674^{* * *}$ & $0.627^{* * *}$ & $0.667^{* * *}$ & $0.682^{* * *}$ \\
\hline Cognitive problems & $0.698^{* * *}$ & $0.673^{* * *}$ & $0.701^{* * *}$ & $0.798^{* * *}$ & $0.748^{* * *}$ \\
\hline Communication & $0.713^{* * *}$ & $0.669^{* * *}$ & $0.691^{* * *}$ & $0.710^{* * *}$ & $0.729^{* * *}$ \\
\hline Total score & $0.730^{* * *}$ & $0.725^{* * *}$ & $0.727^{* * *}$ & $0.753^{* * *}$ & $0.766^{* * *}$ \\
\hline
\end{tabular}

Table 6 Intraclass correlations (ICCS) between Cardiac Module for child self-report and parent cardiac module proxy-report

\begin{tabular}{lll}
\hline Parent-child agreement, ICCs & & \\
\hline PedsQL cardiac module & $\mathbf{5 - 7}$ years & $\mathbf{8 - 1 8}$ years \\
\hline Heart problems and treatment & 0.114 & 0.216 \\
Treatment II & 0.997 & 0.627 \\
Perceived physical appearance & 0.563 & 0.399 \\
Treatment anxiety & 0.411 & 0.116 \\
Cognitive problems & 0.195 & 0.224 \\
Communication & 0.000 & 0.093 \\
Total score & 0.318 & 0.243 \\
\hline
\end{tabular}

ICCs are designated as 0.40 poor to fair agreement, $0.41-0.60$ moderate agreement, $0.61-0.80$ good agreement, and $0.81-1.00$ excellent agreement patients being left alone with their unrecognized emotional distress or, on the other hand, lead to overprotection by parents due to underestimation of their child's coping skills.

\section{Conclusions}

The Italian version of PedsQL ${ }^{\mathrm{TM}} 3.0$ Cardiac Module is valid and reliable for pediatric patients with congenital and acquired HD and may be useful for future research and clinical management. 


\section{Abbreviations}

ADHD: Attention deficit and hyperactivity disorder; CHD: Congenital heart disease; HD: Heart disease; HRQOL: Health-related quality of life; ICCs: Intraclass correlations; IQR: InterQuartile range; PedsQL: Pediatric quality of life; QOL: Quality of life; QOL-SIG TCA: Quality of life-special interest group translation and cultural adaptation; SD: Standard deviation

\section{Supplementary Information}

The online version contains supplementary material available at https://doi. org/10.1186/s12872-021-02157-5.

Additional file 1: PedsQL ${ }^{\mathrm{TM}}$ 3.0 Cardiac Module. The additional file includes all formats of Child Self-Report and Parent Proxy-Report of PedsQL ${ }^{\mathrm{TM}} 3.0$ Cardiac Module.

Additional file 2: Table 7: PedsQL 3.0 Cardiac Module Scores, Reliability and percent Floor and Ceiling Effects for Child Self-Report and Parent Proxy-Report. Table 8: PedsQL 4.0 Generic Module Scores, Reliability and percent Floor and Ceiling Effects for Child Self-Report and Parent ProxyReport. Tables 7 and 8 show number of items, number of subjects, Mean, SD, percent Floor and Ceiling effects for PedsQL 3.0 Cardiac Module Scores and PedsQL 4.0 Generic Module Scores, respectively.

\section{Acknowledgements}

Not applicable.

\section{Authors' contributions}

TGC was a major contributor in writing the manuscript and interpreted the patient data. FB performed her contribution in writing the methods and discussion, and interpreted the patient data. RV and AMDO performed their contribution in writing the background and introduction. FS performed her contribution in revising the manuscript. SG and GC interpreted the patient data. SP and MCDA analyzed and interpreted the patient data and wrote statistical analysis. SG and AR performed their contribution in writing the discussion. All authors read and approved the final manuscript.

\section{Funding}

The authors declare the research had no founding.

\section{Availability of data and materials}

This manuscript includes an 'Availability of data and materials' statement. Data are stored in Hospital database (and available from the corresponding author on reasonable request).

\section{Declarations}

\section{Ethics approval and consent to participate}

The manuscript reports studies involving human participants and human data. It includes a statement on ethics approval and consent of Bambino Gesù Children Hospital Ethics Committee on 05.24.2017 with committee's reference number "1315 OPBG 2017" and consent for publication. Parents or legal tutor of all patients signed a written informed consent. Patients over the age of 16 signed a written informed assent.

\section{Consent for publication}

Not applicable.

\section{Competing interests}

The authors declare that they have no competing interests.

\section{Author details}

${ }^{1}$ Unit of Clinical Psychology, Department of Neuroscience, Bambino Gesù Children's Hospital, IRCCS, Rome, Italy. ${ }^{2}$ Department of Pediatric Cardiology and Cardiac Surgery, Bambino Gesù Children's Hospital, IRCCS, Rome, Italy. ${ }^{3}$ Unit of Clinical Epidemiology, Medical Direction, Bambino Gesù Children's Hospital, IRCCS, Rome, Italy.
Received: 13 August 2020 Accepted: 9 July 2021

Published online: 18 August 2021

\section{References}

1. Pradat P, Francannet C, Harris JA, Robert E. The epidemiology of cardiovascular defects, Part I: a study based on data from three large registries of congenital malformations. Pediatr Cardiol. 2003;24:195-221.

2. Musa NL, Hjortdal V, Zheleva B, Murni IK, Sano S, Schwartz S, et al. The global burden of paediatric heart disease. Cardiol Young. 2017;27:S3-8.

3. Marino BS, Lipkin PH, Newburger JW, Peacock G, Gerdes M, Gaynor JW, et al. Neurodevelopmental outcomes in children with congenital heart disease: evaluation and management: a scientific statement from the American Heart Association. Circulation. 2012;126:1143-72.

4. Politi P, Pinccinelli M, Fusar-Poli P, Klersy C, Campana C, Goggi C, et al. Ten years of "extended" life: quality of life among heart transplantation survivors. Transplantation. 2004:78:257-63.

5. Hövels-Gürich HH, Konrad K, Wiesner M, Minkenberg R, HerpertzDahlmann B, Messmer BJ, et al. Long-term behavioural outcome after neonatal arterial switch operation for transposition of the great arteries. Arch Dis Child. 2002;87:506-10.

6. Berkes A, Pataki I, Kiss M, Kemény C, Kardos L, Varni JW, et al. Measuring health-related quality of life in Hungarian children with heart disease: psychometric properties of the Hungarian version of the Pediatric quality of life inventory TM 4.0 generic core scales and the cardiac module. Health Qual Life Outcomes. 2010;8:14-25.

7. Uzark K, Jones K, Slusher J, Limbers CA, Burwinkle TM, Varni JM. Quality of life in children with heart disease as perceived by children and parents. Pediatrics. 2008;121:e1060-7.

8. Varni JW, Seid M, Kurtin PS. PedsQL 4.0 Reliability and validity of the pediatric quality of life inventory version 4.0 generic core scales in healthy patient populations. Med Care. 2001;39:800-12.

9. Varni JW, Seid M, Rode CA. The PedsQL: measurement model for the pediatric quality of life inventory. Med Care. 1999:37:126-39.

10. Lau JT, Yu XN, Chu Y, Shing MM, Wong EM, Leung TF, et al. Validation of the Chinese version of the pediatric quality of life inventory ${ }^{T M}\left(\right.$ PedsQL $\left.^{T M}\right)$ cancer module. J Pediatr Psychol. 2010;35:99-109.

11. Varni JW, Burwinkle TM, Seid M, Skarr D. The PedsQL $L^{\mathrm{TM}} 4.0$ as a pediatric population health measure: feasibility, reliability and validity. Ambul Pediatr. 2003;3:329-41.

12. Varni JW, Burwinkle TM. The PedsQL ${ }^{\mathrm{TM}}$ as a patient-reported outcome in children and adolescents with attention-deficit/hyperactivity disorder: a population-based study. Health Qual Life Outcomes. 2006;21:4-26.

13. Varni JW, Burwinkle TM, Katz ER, Meeske K, Dickinson P. The PedsQL ${ }^{T M}$ in pediatric cancer: reliability and validity of the pediatric quality of life inventory $^{\mathrm{TM}}$ generic core scales, multidimensional fatigue scale, and cancer module. Cancer. 2002;94:2090-106.

14. Varni JW, Burwinkle TM, Rapoff MA, Kamps JL, Olson N. The PedsQL in pediatric asthma: reliability and validity of the pediatric quality of life inventory generic core scales and asthma module. J Behav Med. 2004;27:297-318.

15. Uzark K, Jones K, Burwinkle TM, Varni JW. The pediatric quality of life inventory ${ }^{\mathrm{TM}}$ in children with heart disease. Prog Pediatr Cardiol. 2003;18:141-8

16. do Nascimento Moraes A, Ramos Ascensão Terreri MT, Esteves Hilário $\mathrm{MO}$, Len CA. Health related quality of life of children with rheumatic heart diseases: reliability of the Brazilian version of the pediatric quality of life inventory ${ }^{\text {TM }}$ cardiac module scale. Health Qual Life Outcomes. 2013;11:198.

17. Hui C, Triandis HC. Measurement in cross-cultural psychology, a review and comparison of strategies. Cross Cult Psychol. 1985;16:131-50.

18. Herdman M, Fox-Rushby J, Badia X. A model of equivalence in the cultura adaptation of HRQL instruments: the universalist approach. Qual Life Res. 1998;7:323-35

19. Bullinger M, Andreson R. Developing and evaluating cross-cultural instruments from minimal requirements to optimal models. Qual Life Res. 1993:2:451-9.

20. Harris-Kojetin LD, Fowler FJ, Brown JA, Schnaier JA, Sweeny SF. The use of cognitive testing to develop and evaluate CAHPSTM core survey items. Med Care. 1999;37:MS10-21. 
21. Wild D, Grove A, Martin M, Ermenco S, McElroy S, Verjee-Lorenz A, et al. Principles of good practice for the translation and cultural adaptation process for patient-reported outcomes (PRO) measures: report of ISPOR task force for translation and cultural adaptation. Value Health. 2005;8:94-104.

22. Cronbach $L$. Coefficient alpha and the internal structure of tests. Psychometrika. 1951:16:297-334.

23. Nunnally JC, Bernstein IR. Psychometric theory. New York: McGraw-Hill; 1994.

24. McHorney CA, Tarlow AR. Individual-patient monitoring in clinical practice: Are available health status surveys adequate? Qual Life Res. 1995:4:293-307.

25. Bartko JJ. The intraclass correlation coefficient as a measure of reliability. Psychol Rep. 1966;19:3-11.

26. Varni JW, Bendo CB, Denham J, Shulman RJ, Self MM, Neigut DA, et al. PedsQL gastrointestinal symptoms modue: feasibility, reliability, and validity. J Pediatr Gastroenterol Nutr. 2014;59:347-55.

27. González-Gil T, Mendoza-Soto A, Alonso-Lloret F, Castro-Murga R, PoseBecerra C, Martín-Arribas MC. The Spanish version of the health-related quality of life questionnaire for children and adolescents with heart disease (PedsQL(TM)). Rev Esp Cardiol (Engl Ed). 2012;65:249-57.

28. Felder-Puig R, Frey E, Proksch K, Varni JW, Gadner H, Topf R. Validation of the German version of the pediatric quality of life Inventory ${ }^{\top M}$ (PedsQL ${ }^{\top M}$ ) in childhood cancer patients off treatment and children with epilepsy. Qual Life Res. 2004;13:223-34.

29. Varni JW, Limbers CA, Burwinkle TM. How young can children reliably and validly self-report their health-related quality of life? an analysis of 8591 children across subgroups with PedsQL ${ }^{\mathrm{TM}} 4.0$ generic core scales. Health Qual Life Outcomes. 2007;5:1-27.
30. De Maso DR, Lauretti A, Spieth L, van der Feen JR, Jay KS, Gauvreau K, et al. Psychosocial factors and quality of life in children and adolescents with implantable cardioverter-defibrillators. Am J Cardiol. 2004;93:582-7.

31. Ternstedt BM, Wall K. Quality of life 20 and 30 years after surgery in patients operated for tetralogy of Fallot and for atrial septal defect. Ped Cardiol. 2001;22:128-32.

32. Lane DA, Lip GYH, Millane TA. Quality of life in adults with congenital heart disease. Heart. 2002;88:71-5.

33. Cohen M, Mansoor D, Langut H, Lorber A. Quality of life, depressed mood, and self-esteem in adolescents with heart disease. Psychosom Med. 2007:69:313-8.

34. Boekaerts M, Röder I. Stress, coping, and adjustment in children with a chronic disease: a review of the literature. Disabil Rehabil. 1999;21:311-37.

35. Curtis CE, Luby JL. Depression and social functioning in preschool children with chronic medical conditions. J Pediatr. 2008;153:408-13.

36. Theunissen NC, Vogels TG, Koopman HM, Verrips GH, Zwinderman KA, Verloove-Vanhorick SP, et al. The proxy problem: child report versus parent report in health-related quality of life research. Qual Life Res. 1988;7:387-97.

37. Birks Y, Sloper P, Lewin R, Parsons J. Exploring health-related experiences of children and young people with congenital heart disease. Health Expect. 2007;10:16-29.

\section{Publisher's Note}

Springer Nature remains neutral with regard to jurisdictional claims in published maps and institutional affiliations.
Ready to submit your research? Choose BMC and benefit from:

- fast, convenient online submission

- thorough peer review by experienced researchers in your field

- rapid publication on acceptance

- support for research data, including large and complex data types

- gold Open Access which fosters wider collaboration and increased citations

- maximum visibility for your research: over $100 \mathrm{M}$ website views per year

At BMC, research is always in progress.

Learn more biomedcentral.com/submissions 